ORIGINAL PAPER

\title{
EVALUATION OF POLYMORPHISMS IN MICRORNA BIOSYNTHESIS genes and Risk of LARYNgeal CANCER in The Polish POPULATION
}

\author{
Antoni Bruzgielewicz ${ }^{1}$, Ewa Osuch-Wójcikiewicz ${ }^{1}$, Anna Walczak ${ }^{2}$, Alicja Nowak ${ }^{2}$, \\ HeLEN UCZKowsKi ${ }^{2}$, IRENEUSZ MajSTEREK ${ }^{2}$
}

${ }^{1}$ Otolaryngology Department, Medical University of Warsaw, Warsaw, Poland

${ }^{2}$ Department of Clinical Chemistry and Biochemistry, Medical University of Lodz, Lodz, Poland

\begin{abstract}
MicroRNAs are the largest group of short regulatory RNAs. They regulate genes participating in many physiological and pathological processes. The role of micro RNAs in cancer development is also considerable. Therefore, the aim of this study was to evaluate the relationship between DROSHA (rs6877842) and DGCR8 (rs417309, rs1640299) gene polymorphisms with risk of occurrence of laryngeal cancer.

The study included 100 patients and 100 healthy subjects. Genomic DNA was extracted from formalin-fixed, paraffin-embedded tissues. Analysis of the gene polymorphisms was performed using TaqMan SNP Genotyping Assay.

The rs417309 AA genotype was found to be correlated with increased risk of larynx cancer. The rs 1640299 TG and rs6877842 CG heterozygotes were significantly inversely associated with the presence of larynx cancer. Additionally, rs417309 AA genotype increased the risk of larynx cancer in the T1 stage, and the rs1640299 TG heterozygote occurred more frequently in the control group than those in the $\mathrm{T} 3$ and $\mathrm{T} 4$ stage.

The rs417309 and rs1640299 polymorphisms of the DGCR8 gene as well as rs6877842 of the DROSHA gene might be associated with a risk of laryngeal cancer occurrence in the Polish population.
\end{abstract}

Key words: laryngeal cancer, gene polymorphism, microRNA biosynthesis genes, carcinogenesis.

\section{Introduction}

Laryngeal cancer (LC) is a multifactorial disease, its development affected by both genetic and environmental factors. Tobacco smoking, alcohol consumption and human papillomavirus infection increase the risk of developing this type of cancer [1]. Laryngeal cancer constitutes about $30 \%$ of all malignant cancers of the head and neck, and is related to low survival rates [2]. Because the mortality of cancer is closely associated with late detection of the disease, more specific markers are essential for early diagnosis. The molecular mechanism underlying the development of LC is still poorly understood. Many studies have shown that a defective DNA repair mechanism, impaired cell cycle and aberrant expression of the metalloproteinases might increase the risk of LC occurrence $[3,4,5,6,7,8,9]$.

In recent years, many studies have focused on investigating the role of microRNAs (miRNAs) in cancer development. miRNAs are the largest group of 
short regulatory RNAs. Since the discovery of the first miRNA in 2001, each year the number of newly discovered miRNA has been growing rapidly $[10$, 11]. In 2013, Friedländer $e t$ al. reported 2,469 novel human miRNA candidates, of which 1,098 have been validated by in-house and published experiments [12]. After two years, in 2015, Londin et al. identified 3,707 statistically significant novel mature miRNAs [13]. They regulate $30 \%$ of the genes in the human genome participating in many physiological and pathological processes. MicroRNAs are short non-coding RNAs of 20-24 nucleotides. Most miRNA genes are transcribed by RNA polymerase II. The initial transcript, pri-miRNA, adopts a hairpin structure. Maturation of pri-miRNA involves two enzymes from the RNase III family: Drosha and Dicer. In the nucleus, the microprocessor complex, containing Drosha enzyme and DGCR8 protein, trims the RNA molecule at the $3^{\prime}$ and $5^{\prime}$ end. In this way, a molecule of $\sim 70$ nucleotides is formed, called a pre-miRNA, which is subsequently exported to the cytoplasm by exportin 5 (XPO5) $[14,15]$. In the cytoplasm, pre-miRNA undergoes further trims by a protein complex containing DICER and TRBP, thereby forming a single-stranded mature miRNA, which subsequently interacts with the RNA-induced silencing complex (RISC), which consists of key proteins such as AGO2 and GW182. The mature miRNA with RISC complex binds to the 3'-UTR region of the mRNA, affecting the level of the target gene expression $[15,16]$.

Many previous studies have shown that miRNAs participate in various processes involved in oncogenesis, such as proliferation, cell cycle control, apoptosis, differentiation, migration and metabolism. It was found that miRNAs can not only regulate the expression of multiple oncogenes and tumor suppressor genes, but may themselves act as oncogenes and suppressors [17]. Some changes in the genes encoding miRNAs as well as in miRNA machinery genes, including single nucleotide polymorphisms (SNPs), may affect the structure and function of the produced transcript, but also the level of their expression. Therefore, the aim of this study was to investigate the relationship of SNPs of DROSHA (rs6877842) and DGCR8 (rs417309, rs1640299) genes with risk of occurrence of laryngeal cancer in the Polish population.

\section{Material and methods}

\section{Subjects}

In the present study we investigated a total of 200 unrelated Caucasian subjects. Among them were 100 subjects with diagnosed head and neck cancer located in the larynx (87 males and 13 females; mean age $61 \pm 7)$ and 100 subjects constituting a control group without cancer (82 males and 18 females; mean age $65 \pm 9$ ). The larynx cancer samples were obtained from patients who underwent surgical operations such as partial or complete laryngectomy at the Public Central Clinical Hospital in Warsaw, Poland. Cancer status and type were confirmed with histopathology examination. Samples were provided as formalin-fixed and paraffin-embedded tissue specimens. The control group comprised subjects without neoplastic disease or family history of cancer. Material constituting the control group was blood collected in $5 \mathrm{ml}$ EDTA tubes.

Before proceeding to the study, subjects from the control group and study group did not take drugs, including antibiotics and steroids. The TNM Classification of Malignant Tumors system was used to classify patients enrolled in the study. Furthermore, the neoplastic grade of every tumor was also assessed using a three-tier grading scheme: G1 - well-differentiated tumor, G2 - moderately differentiated tumor, and G3 - poorly differentiated. Moreover, patients were classified into three groups according to their smoking habits: subjects smoking less than 10 years, subjects smoking for 10-40 years, and subjects smoking for more than 40 years. According to their smoking attitude they were classified as follows: non-smokers, subjects smoking less than 20 cigarettes per day and subjects smoking at least 20 cigarettes per day.

The study material and patients' data were obtained from the Head and Neck Neoplasm Surgery Departments, Medical University of Warsaw, Poland. The Ethics Committee of the Medical University of Warsaw has approved the study concept and design. Each patient involved in the study has been informed in outline about the research and has signed the examination enrolment agreement.

\section{DNA extraction}

DNA was extracted from the formalin-fixed, paraffin-embedded tissues using the BiOstic FFPE Tissue DNA Isolation Kit (MOBIO), based on the manufacturer's protocol. After extraction, DNA purity and concentration were measured by comparing the absorbance at 260 and $280 \mathrm{~nm}$ using a Synergy HT microplate reader (BioTek). DNA was diluted to a concentration of $5 \mathrm{ng} / \mu \mathrm{l}$.

\section{Genotyping assay}

The genotyping of DROSHA and DGCR8 polymorphic variants was conducted by TaqMan SNP Genotyping Assay with a commercially available primer probe sets (Table I) (Applied Biosystems, Foster City, CA, USA) and TaqMan Genotyping Master Mix (Applied Biosystems, Foster City, CA, USA) carried out on Mx3005P (Agilent Technologies, Santa Clara, CA, USA) according to the manufacturer's protocol. 
PCR was performed under universal thermal cycling conditions: initial denaturation step at $95^{\circ} \mathrm{C}$ for 10 min, followed by 40 cycles of DNA denaturation at $95^{\circ} \mathrm{C}$ for $30 \mathrm{~s}$ and oligonucleotide annealing/strand elongation at $60^{\circ} \mathrm{C}$ for $30 \mathrm{~s}$. Evaluation of $20 \%$ of randomly chosen samples was repeated to confirm the previously obtained results.

\section{Statistical analysis}

The observed genotype frequencies for each polymorphism were evaluated using the Hardy-Weinberg equilibrium test, using the $\chi^{2}$ test. Genotype distribution with the outcome $\mathrm{P}<0.05$ was considered as not consistent with the Hardy-Weinberg equilibrium (HWE).

The $\chi^{2}$ analysis was also used to test the significance of the differences between distributions of genotypes in cancer patients and controls. The association between case-control status and each polymorphism, measured by the odds ratio (OR) and its corresponding $95 \%$ confidence interval (CI), was estimated using an unconditional multiple logistic regression model. If expected frequencies in the $2 \times 2$ contingency table were smaller than 5 , the Fisher exact probability test was performed. Statistical significance was defined as $\mathrm{p}<0.05$. All analyses were performed using STATISTICA 6.0 software (StatSoft, Tulsa, OK, USA).

\section{Results}

We used a $\chi^{2}$ test to assess whether the DROSHA and DGCR8 single nucleotide polymorphism distribution were in HWE among the controls. Among the control group, the genotype distributions of
Table I. Assay number of applied TaqMan SNP Genotyping Assay (Thermo Fisher Scientific)

\begin{tabular}{cl}
\hline SNP ID & AssaY ID \\
\hline rs417309 & C_ 2539468_20 \\
\hline rs1640299 & C_7543549_20 \\
\hline rs6877842 & C_1153852_10 \\
\hline
\end{tabular}

rs417309, rs1640299 and rs6877842 were in agreement with HWE ( $>>0.05$ ).

In Table II we have presented the general distribution of genotypes in both patient and control subject groups. The analysis showed that the rs417309 GG genotype is correlated with decreased risk of larynx cancer $(\mathrm{OR}=0.29,95 \% \mathrm{CI}: 1.057-11.265, \mathrm{p}=$ 0.031). The rs1640299 TG as well as rs6877842 CG heterozygotes were also significantly inversely associated with the presence of larynx cancer $(\mathrm{OR}=0.528$, 95\% CI: $0.0888-0.9464, \mathrm{p}=0.031$; OR $=0.546$, 95\% CI: 0.304-0.981, $\mathrm{p}=0.042$; respectively).

Next, we divided the patient group according to the tumor stage. As shown in Table IIIA, rs417309 GG genotype facilitated the decreased risk of larynx cancer in the $\mathrm{T} 1$ subgroup $(\mathrm{OR}=0.058,95 \% \mathrm{CI}$ : 0.008-0.384, $\mathrm{p}=0.007$ ). In addition, our results indicated that the rs1640299 TG heterozygote occurred more frequently in the control group than in the $\mathrm{T} 3$ and $\mathrm{T} 4$ groups $(\mathrm{OR}=0.082,95 \% \mathrm{CI}$ : $0.023-0.292, \mathrm{p}<0.0001 ; \mathrm{OR}=0.327,95 \% \mathrm{CI}$ : 0.137-0.779, $\mathrm{p}=0.009$, respectively) - Table IIIB. A similar association was observed in the group of $\mathrm{T} 4$ patients, where rs6877842 TG genotype was more prevalent than in the control group $(\mathrm{OR}=0.407$, 95\% CI: 0.174-0.95, $\mathrm{p}=0.035$; Table IIIB). There

Table II. Correlation between selected DICER and DGCR8 gene polymorphisms and laryngeal cancer

\begin{tabular}{|c|c|c|c|c|c|c|c|}
\hline \multirow[b]{2}{*}{ RS NO. } & \multirow[b]{2}{*}{ GENOTYPE } & \multirow{2}{*}{$\begin{array}{c}\text { Controls } \\
\text { No. }\end{array}$} & \multirow{2}{*}{$\frac{\text { Patients }}{\text { No. }}$} & \multicolumn{4}{|c|}{ 95\% CONFIDENCE INTERVALS } \\
\hline & & & & ODDS RATIO & LOWER LIMIT & UPPER LIMIT & $\mathbf{P}$ \\
\hline \multicolumn{8}{|c|}{ DGCR8 } \\
\hline \multirow[t]{3}{*}{417309} & A & 4 & 12 & Ref. & Ref. & Ref. & Ref. \\
\hline & $A G$ & 27 & 28 & 0.381 & 0.0833 & 1.7413 & 0.207 \\
\hline & G & 69 & 60 & 0.2899 & 0.0888 & 0.9464 & 0.031 \\
\hline \multirow{3}{*}{$\begin{array}{c}1640299 \\
(\mathrm{REV})\end{array}$} & $\mathrm{T}$ & 36 & 52 & Ref. & Ref. & Ref. & Ref. \\
\hline & TG & 55 & 42 & 0.529 & 0.295 & 0.949 & 0.032 \\
\hline & G & 9 & 6 & 0.462 & 0.151 & 1.410 & 0.168 \\
\hline \multicolumn{8}{|c|}{ DROSHA } \\
\hline \multirow[t]{3}{*}{6877842} & $\mathrm{C}$ & 44 & 60 & Ref. & Ref. & Ref. & Ref. \\
\hline & CG & 47 & 35 & 0.546 & 0.304 & 0.981 & 0.042 \\
\hline & G & 9 & 5 & 0.407 & 0.128 & 1.300 & 0.121 \\
\hline
\end{tabular}

$R E V$ - single nucleotide polymorphism estimated on the reverse orientation strand 


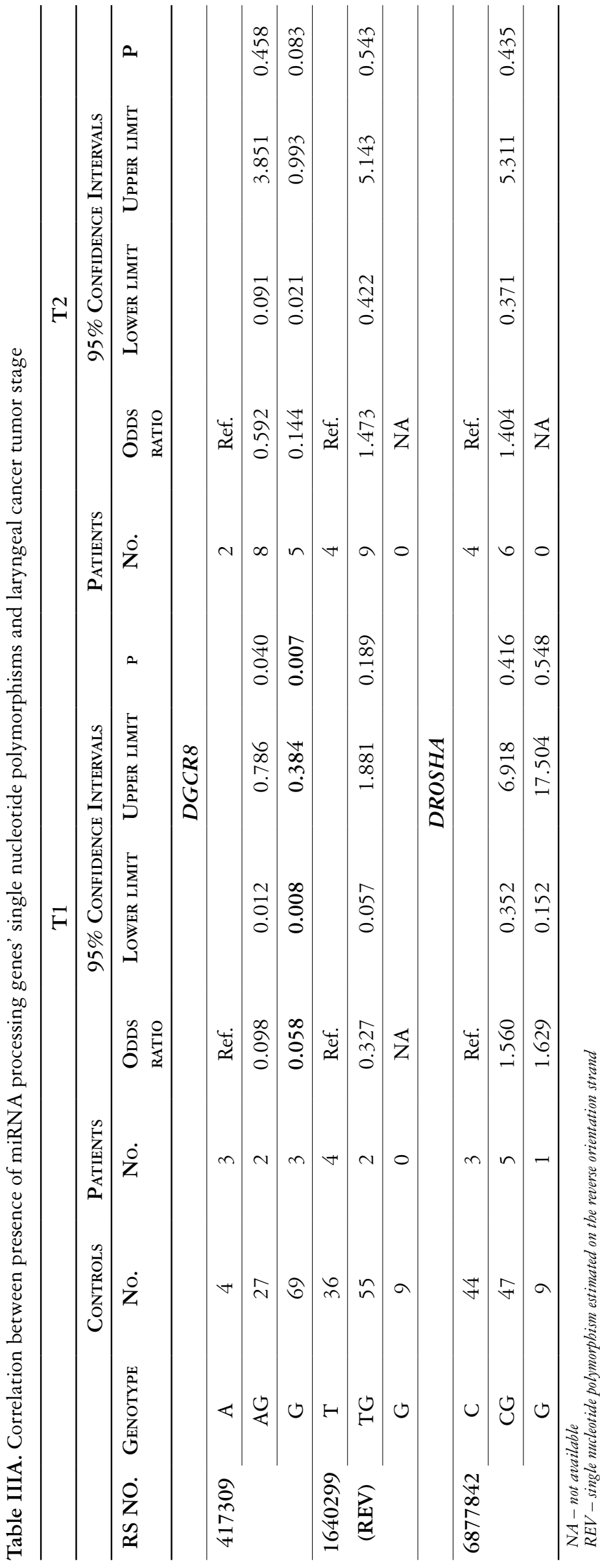

were no other associations determined by the tumor size. Analysis of the gene polymorphisms in correlation with neoplastic grading is presented in Table IV. However, there were no statistically significant associations of the DGCR8 (rs417309 and rs1640299) and DROSHA (rs6877842) gene polymorphisms with progression of LC based on neoplastic grade $(\mathrm{p}>0.05)$.

Tables $\mathrm{V}$ and VI present the correlation of presence of miRNA processing genes' single nucleotide polymorphisms with patients' gender and age (respectively). Distributions of genotypes and allele frequencies of DGCR 8 (rs417309 and rs1640299) and DROSHA (rs6877842) gene polymorphisms with regard to gender did not show any significant differences ( $p>0.05$ ) (Table V). Similarly, we did not observe any relationship between the studied gene polymorphisms and patients' age $(\mathrm{p}>0.05)$ (Table VI).

\section{Discussion}

There is a growing amount of information on the role of microRNAs in the regulation of processes closely related to the development of cancer, including proliferation, differentiation, and apoptosis. Polymorphisms in genes encoding miRNAs can lead to changes in many biological processes. Moreover, single nucleotide alterations within miRNA machinery genes, such as DROSHA, DGCR8, DICER1, and XPO5, can also contribute to disturbances in the functioning of miRNAs, and consequently might substantially affect the initiation and progression of cancer $[18$, 19]. In our study, we examined the relationship of genes polymorphisms of DROSHA and $D G C R 8$, which are responsible for the initial step in the synthesis of miRNAs in the nucleus, with the development of laryngeal cancer. During the formation of miRNA in the cell nucleus, RNA polymerase transcribes the pri-miRNA and then DROSHA and its cofactor DGCR8, modify pri-miRNA into precursor-miRNA (pre-miRNA) by deleting the $5^{\prime}$ cap and the 3' poly(A) tail. Consequently pre-miRNA forms a hairpin structure and in this form is transported to the cytoplasm by XPO5 [15].

Our study showed that CG genotype of rs6877842 polymorphism of the DROSHA gene is related to a significant decrease of the risk of LC development $(\mathrm{OR}=0.55,95 \%$ CI: $0.30-0.98, \mathrm{p}=0.042)$. This is the first research considering the association of this 
polymorphism with the risk of larynx cancer. Some studies have shown a relationship between the rs6877842 polymorphism and development of other types of cancer [20, 21]. The study conducted by Li et al. (2014) confirmed the effect of this polymorphism on the survival rate of patients with T-cell lymphoma. Patients with the $\mathrm{C}$ allele of this polymorphism had increased overall survival compared with those carrying the GG genotype (HR, 0.27; 95\% CI, 0.11-0.67; p = 0.005) [21]. The rs6877842 polymorphism is located in the promoter of the DROSHA gene, and hence can affect the level of protein expression. A study conducted to demonstrate the role of DROSHA in neuroblastoma development indicated its low expression in this type of cancer, which was associated with miRNA downregulation in advanced stages of the disease and was correlated with a poor prognosis [22]. Moreover, an in vitro study also showed that knockdown of the DROSHA gene led to intensive growth of neuroblastoma cell lines [22]. Similarly, other studies have demonstrated down-regulated DROSHA expression in breast cancer, epithelial skin cancer and nasopharyngeal carcinoma [23, 24, 25]. Therefore, participation of DROSHA in carcinogenesis seems to be much more likely.

Another crucial protein involved in the maturation of microRNAs is DGCR8. Several studies have indicated the participation of this protein in cancer development. There has been observed a significant increase in the expression of DGCR8 in pleomorphic adenomas of the salivary gland as well as in the basal cells and squamous cell carcinomas compared with healthy controls $[26,27]$. In our study we assessed the relationship of two SNPs (rs417309, rs 1640299) of the DGCR8 gene with risk of laryngeal cancer developing. Both polymorphisms are located in the 3'-UTR, which is the binding site of miRNAs, and hence may affect the efficiency of miRNA processing [28]. The TG genotype of rs1640209 significantly decreased the LC development risk $(\mathrm{OR}=0.53$, 95\% CI: 0.29-0.95, $\mathrm{p}=0.032$ ). Moreover, our results indicated that the rs $1640299 \mathrm{TG}$ heterozygote occurred more frequently in the control group than in the $\mathrm{T} 3$ and $\mathrm{T} 4$ tumor samples (OR $=0.082$, 95\% CI: 0.023-0.292, $\mathrm{p}<0.0001 ; \mathrm{OR}=0.327,95 \% \mathrm{CI}: 0.137-$ $0.779, \mathrm{p}=0.009$, respectively). The GG genotype of rs417309 also showed a statistically significant decrease in the risk of LC occurrence $(\mathrm{OR}=0.29,95 \% \mathrm{CI}: 1.057-11.265, \mathrm{p}$ $=0.031$ ). To our knowledge, this is the first

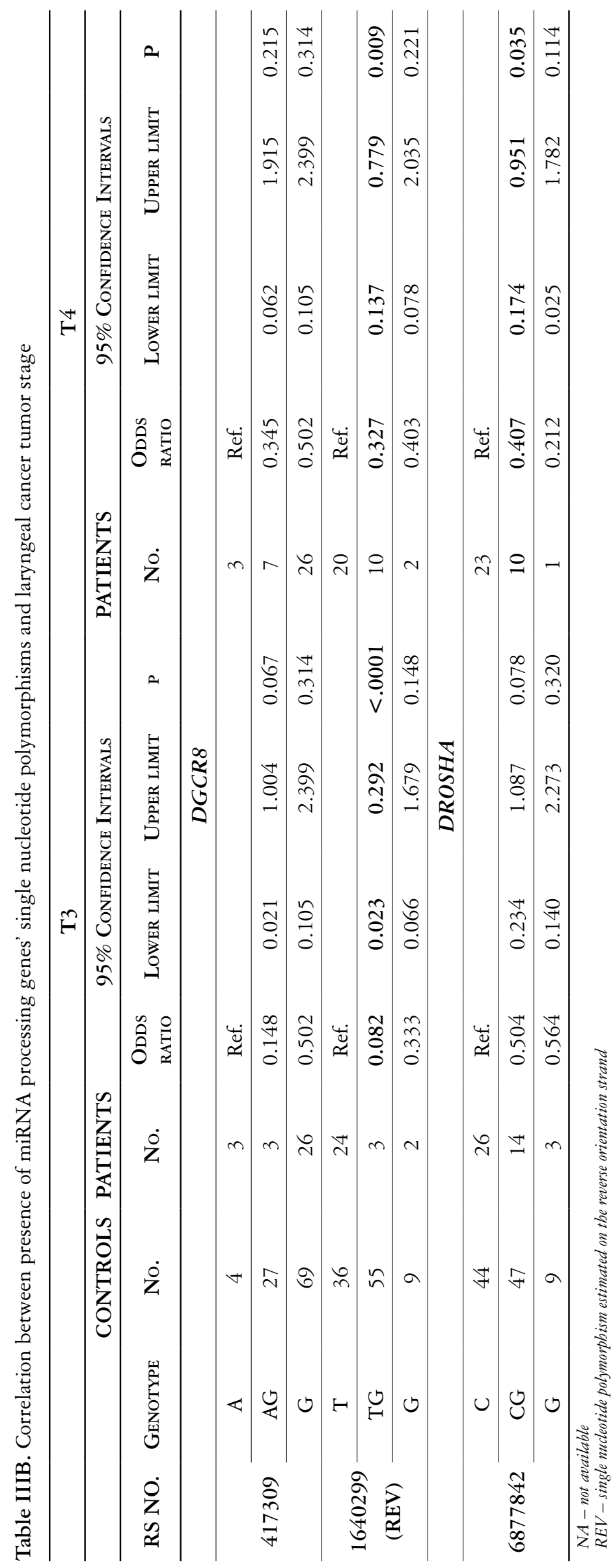


Table IV. Correlation between presence of miRNA processing genes' single nucleotide polymorphisms and histopathological three-tier grading scheme

\begin{tabular}{|c|c|c|c|c|c|c|c|}
\hline \multirow[b]{2}{*}{ RS NO. } & \multirow[b]{2}{*}{ GENOTYPE } & \multirow{2}{*}{$\frac{\mathrm{G} 1+\mathrm{G} 2}{\mathrm{No} .}$} & \multirow{2}{*}{$\frac{\text { G3 }}{\text { No. }}$} & \multicolumn{4}{|c|}{ 95\% CONFIDENCE INTERVALS } \\
\hline & & & & OdDS RATIO & LOWER LIMIT & UPPER LIMIT & $\mathbf{P}$ \\
\hline \multicolumn{8}{|c|}{ DGCR8 } \\
\hline \multirow[t]{3}{*}{417309} & A & 6 & 1 & Ref. & Ref. & Ref. & Ref. \\
\hline & AG & 19 & 2 & 0.6316 & 0.0483 & 8.252 & 0.5941 \\
\hline & G & 34 & 7 & 1.2353 & 0.1279 & 11.9326 & 0.6702 \\
\hline \multirow{3}{*}{$\begin{array}{c}1640299 \\
(\mathrm{REV})\end{array}$} & $\mathrm{T}$ & 29 & 5 & Ref. & Ref. & Ref. & Ref. \\
\hline & TG & 29 & 3 & 0.6 & 0.1311 & 2.7464 & 0.3895 \\
\hline & G & 4 & 0 & NA & & & \\
\hline \multicolumn{8}{|c|}{$D R O S H A$} \\
\hline \multirow[t]{3}{*}{6877842} & $\mathrm{C}$ & 3 & 1 & Ref. & Ref. & Ref. & Ref. \\
\hline & CG & 21 & 3 & 0.4286 & 0.0329 & 5.5786 & 0.481 \\
\hline & $\mathrm{G}$ & 36 & 4 & 0.3333 & 0.0277 & 4.0117 & 0.3941 \\
\hline
\end{tabular}

$R E V$ - single nucleotide polymorphism estimated on the reverse orientation strand

Table V. Correlation of presence of miRNA processing genes' single nucleotide polymorphisms with patients' gender

\begin{tabular}{|c|c|c|c|c|c|c|c|}
\hline \multirow[b]{2}{*}{ RS NO. } & \multirow[b]{2}{*}{ GENOTYPE } & \multirow{2}{*}{$\begin{array}{c}\text { WOMEN } \\
\text { No. } \\
\end{array}$} & \multirow{2}{*}{$\begin{array}{c}\text { MEN } \\
\text { No. } \\
\end{array}$} & \multicolumn{4}{|c|}{ 95\% CONFIDENCE INTERVALS } \\
\hline & & & & ODDS RATIO & LOWER LIMIT & UPPER LIMIT & $\mathbf{P}$ \\
\hline \multicolumn{8}{|c|}{$D G C R 8$} \\
\hline \multirow[t]{3}{*}{417309} & A & 3 & 9 & Ref. & Ref. & Ref. & Ref. \\
\hline & AG & 4 & 24 & 2 & 0.3721 & 10.7485 & 0.3461 \\
\hline & G & 4 & 56 & 4.6667 & 0.8925 & 24.4015 & 0.0853 \\
\hline \multirow{3}{*}{$\begin{array}{c}1640299 \\
(\mathrm{REV})\end{array}$} & $\mathrm{T}$ & 5 & 45 & Ref. & Ref. & Ref. & Ref. \\
\hline & TG & 7 & 37 & 0.5873 & 0.1721 & 2.0039 & 0.3928 \\
\hline & G & 3 & 6 & 0.2222 & 0.042 & 1.1754 & 0.0945 \\
\hline \multicolumn{8}{|c|}{ DROSHA } \\
\hline \multirow[t]{3}{*}{6877842} & $\mathrm{C}$ & 0 & 5 & Ref. & Ref. & Ref. & Ref. \\
\hline & CG & 3 & 32 & NA & & & \\
\hline & $\mathrm{G}$ & 11 & 49 & NA & & & \\
\hline
\end{tabular}

$R E V$ - single nucleotide polymorphism estimated on the reverse orientation strand

case-control study evaluating the association between rs417309 as well as rs1640299 polymorphisms of the DGCR8 gene and laryngeal cancer risk occurrence. The studies conducted by Lin et al. and by Yang et al. showed no significant difference between rs417309 and rs1640299 polymorphisms and risk of renal cell carcinoma and bladder cancer development, respectively [28, 29]. Jiang et al. observed that rs417309 was associated with increased breast cancer risk in Chinese women (GG vs. AG: OR = 1.53, 95\% CI: 1.02-2.31, $\mathrm{p}=0.04$; per allele $\mathrm{OR}=1.59,95 \% \mathrm{CI}: 1.09-2.33$, $\mathrm{p}=0.017)[19]$. Because this polymorphism is locat- ed at the binding sites of $\mathrm{miR}-106 \mathrm{~b}$ and $\mathrm{miR}-579$ in the 3'-UTR of DGCR8, Jiang et al. assessed whether the rs417309 variant affects the binding capacity of miRNAs. Using luciferase assays they found significantly higher expression levels of miR-106b and miR-579 $\left(\mathrm{p}=3.31 \times 10^{-7}, \mathrm{p}=9.29 \times 10^{-7}\right.$, respectively $)$ with the rs417309 A allele than the $G$ allele, which may lead to impairment of miRNA binding and thereby modify the process of miRNA maturation and consequently may play a pivotal role in carcinogenesis [19]. Furthermore, some studies have reported that expression of miR-106b is significantly increased in breast 
Table VI. Correlation of presence of miRNA processing genes' single nucleotide polymorphisms with patients' age

\begin{tabular}{|c|c|c|c|c|c|c|c|}
\hline \multirow[b]{2}{*}{ RS NO. } & \multirow[b]{2}{*}{ GENOTYPE } & \multirow{2}{*}{$\begin{array}{c}\text { UP TO } 60 \text { YEARS } \\
\text { OF AGE } \\
\text { No. }\end{array}$} & \multirow{2}{*}{$\begin{array}{c}60 \text { YEARS OF AGE AND } \\
\text { OLDER } \\
\text { No. }\end{array}$} & \multicolumn{4}{|c|}{$\begin{array}{l}\text { 95\% CONFIDENCE } \\
\text { INTERVALS }\end{array}$} \\
\hline & & & & ODDS RATIO & LOWER LIMIT & UPPER LIMIT & $\mathbf{P}$ \\
\hline \multicolumn{8}{|c|}{ DGCR8 } \\
\hline \multirow{3}{*}{417309} & A & 6 & 6 & Ref. & Ref. & Ref. & Ref. \\
\hline & AG & 11 & 17 & 1.5455 & 0.3958 & 6.035 & 0.5323 \\
\hline & G & 25 & 35 & 1.44 & 0.4162 & 4.9827 & 0.5656 \\
\hline \multirow{3}{*}{$\begin{array}{c}1640299 \\
(\mathrm{REV})\end{array}$} & $\mathrm{T}$ & 23 & 29 & Ref. & Ref. & Ref. & Ref. \\
\hline & TG & 21 & 21 & 0.7931 & 0.3508 & 1.793 & 0.5777 \\
\hline & $G$ & 4 & 2 & 0.3966 & 0.0666 & 2.3596 & 0.2707 \\
\hline \multicolumn{8}{|c|}{ DROSHA } \\
\hline \multirow{3}{*}{6877842} & $\mathrm{C}$ & 1 & 4 & Ref. & Ref. & Ref. & Ref. \\
\hline & CG & 20 & 15 & 0.1875 & 0.019 & 1.854 & 0.1413 \\
\hline & $\mathrm{G}$ & 27 & 33 & 0.3056 & 0.0322 & 2.8979 & 0.2766 \\
\hline
\end{tabular}

$R E V$ - single nucleotide polymorphism estimated on the reverse orientation strand

cancer tissues, and in MDA-MB-231 cell lines miR$106 \mathrm{~b}$ promoted a higher frequency of metastasis [19].

In light of recent reports, the role of microRNAs in cancer development is considerable. The miRNAs are involved in all aspects of cancer biology, such as proliferation, apoptosis, migration, and angiogenesis. Our results suggest that rs417309 and rs1640299 polymorphisms of the DGCR8 gene as well as rs6877842 of the DROSHA gene, the gene products of which are implicated in miRNA maturation, might be associated with a risk of laryngeal cancer occurrence in the Polish population. These findings require verification by further research with a larger sample size to explain the mechanisms by which polymorphisms of miRNA machinery genes affect laryngeal cancer development.

This work was supported by a grant from National Centre for Research and Development: NR 13-0101-10.

The authors declare no conflict of interest.

\section{References}

1. McKaig RG, Baric RS, Olshan AF. Human papillomavirus and head and neck cancer: epidemiology and molecular biology. Head Neck 1998; 20: 250-265.

2. Koufman JA, Burke AJ. The etiology and pathogenesis of laryngeal carcinoma. Otolaryngol Clin North Am 1997; 30: $1-19$.

3. Liu RR, Li MD, Li T, et al. Matrix metalloproteinase 2 (MMP2) protein expression and laryngeal cancer prognosis: a meta analysis. Int J Clin Exp Med 2015; 8: 2261-2266.

4. Sun YN, Li Y. Expression of mRNA for membrane-type 1, 2, and 3 matrix metalloproteinases in human laryngeal cancer. Chin Med Sci J 2004; 19: 170-173.
5. Peschos D, Stefanou D, Vougiouklakis T, et al. Cell cycle proteins in laryngeal cancer: role in proliferation and prognosis. J Exp Clin Cancer Res 2005; 24: 431-437.

6. Korkmaz H, Du W, Yoo GH, et al. Prognostic significance of G1 cell-cycle inhibitors in early laryngeal cancer. Am J Otolaryngol 2005; 26: 77-82.

7. Romanowicz-Makowska H, Smolarz B, Gajęcka M, et al. Polymorphism of the DNA repair genes RAD51 and XRCC2 in smoking- and drinking-related laryngeal cancer in a Polish population. Arch Med Sci 2012; 8: 1065-1075.

8. Walczak A, Rusin P, Dziki W, et al. Evaluation of DNA double strand breaks repair efficiency in head and neck cancer. DNA Cell Biol 2012; 31: 298-305.

9. Rusin P, Olszewski J, Morawiec-Bajda A, et al. Role of impaired DNA repair in genotoxic susceptibility of patients with head and neck cancer. Cell Biol Toxicol 2009; 25: 489-497.

10. Lee RC, Ambros V. An extensive class of small RNAs in Caenorhabditis elegans. Science 2001; 294: 862-864.

11. Lagos-Quintana M, Rauhut R, Lendeckel W, Tuschl T. Identification of novel genes coding for small expressed RNAs. Science 2001; 294: 853-858.

12. Friedländer MR, Lizano $\mathrm{E}$, Houben $\mathrm{AJ}$, et al. Evidence for the biogenesis of more than 1,000 novel human microRNAs. Genome Biol 2014; 15: R57.

13. Londin E, Loher P, Telonis AG, et al. Analysis of 13 cell types reveals evidence for the expression of numerous novel primateand tissue-specific microRNAs. Proc Natl Acad Sci U S A 2015; 112: E1106-E1115.

14. Williams AE. Functional aspects of animal microRNAs. Cell Mol Life Sci 2008; 65: 545-562.

15. Ouellet DL, Perron MP, Gobeil LA, et al. MicroRNAs in gene regulation: when the smallest governs it all. J Biomed Biotechnol 2006; 2006: p. 69616.

16. Bartel DP. MicroRNAs: genomics, biogenesis, mechanism, and function. Cell 2004; 116: 281-297.

17. Zhang B, Pan X, Cobb GP, Anderson TA. microRNAs as oncogenes and tumor suppressors. Dev Biol 2007; 302: 1-12.

18. Cho SH, Ko JJ, Kim JO, et al. 3'-UTR Polymorphisms in the MiRNA Machinery Genes DROSHA, DICER1, RAN, and XPO5 Are Associated with Colorectal Cancer Risk in a Korean Population. PLoS One 2015; 10: e0131125. 
19. Jiang Y, Chen J, Wu J, et al. Evaluation of genetic variants in microRNA biosynthesis genes and risk of breast cancer in Chinese women. Int J Cancer 2013; 133: 2216-2224.

20. Rah H, Jeon YJ, Lee B, et al. Association of polymorphisms in microRNA machinery genes (DROSHA, DICER1, RAN, and $\mathrm{XPO} 5$ ) with risk of idiopathic primary ovarian insufficiency in Korean women. Menopause 2013; 20: 1067-1073.

21. Li X, Tian X, Zhang B, Chen J. Polymorphisms in microRNA-related genes are associated with survival of patients with T-cell lymphoma. Oncologist 2014; 19: 243-249.

22. Lin RJ, Lin YC, Chen J, et al. microRNA signature and expression of Dicer and Drosha can predict prognosis and delineate risk groups in neuroblastoma. Cancer Res 2010; 70: 7841-7850.

23. Guo X, Liao Q, Chen P, et al. The microRNA-processing enzymes: Drosha and Dicer can predict prognosis of nasopharyngeal carcinoma. J Cancer Res Clin Oncol 2012; 138: 49-56.

24. Sand M, Gambichler T, Skrygan M, et al. Expression levels of the microRNA processing enzymes Drosha and dicer in epithelial skin cancer. Cancer Invest 2010; 28: 649-653.

25. Yan, M., Huang HY, Wang T, et al. Dysregulated expression of dicer and drosha in breast cancer. Pathol Oncol Res 2012; 18: 343-348.

26. Zhang X, Cairns M, Rose B, et al. Alterations in miRNA processing and expression in pleomorphic adenomas of the salivary gland. Int J Cancer 2009; 124: 2855-2863.

27. Sand M, Skrygan M, Georgas D, et al. Expression levels of the microRNA maturing microprocessor complex component DGCR8 and the RNA-induced silencing complex (RISC) components argonaute- 1 , argonaute- 2 , PACT, TARBP1, and TARBP2 in epithelial skin cancer. Mol Carcinog 2012; 51: 916-922.

28. Yang H, Dinney CP, Ye Y, et al. Evaluation of genetic variants in microRNA-related genes and risk of bladder cancer. Cancer Res 2008; 68: 2530-2537.

29. Lin J, Horikawa Y, Tamboli P, et al. Genetic variations in microRNA-related genes are associated with survival and recurrence in patients with renal cell carcinoma. Carcinogenesis 2010; 31: 1805-1812.

\section{Address for correspondence}

\section{Alicja Nowak}

Department of Clinical Chemistry and Biochemistry

Medical University of Lodz

Hallera 1 square

90-647 Lodz, Poland

e-mail: alicjanowak87@wp.pl 